\title{
Synthesis of the Macrolactone Cores of Maltepolides via a Diene-Ene Ring-Closing Metathesis Strategy
}

\author{
Man Ki Sit, ${ }^{\dagger}$ Hui Hui Cao, ${ }^{\dagger}$ Yan-Dong Wu, ${ }^{\dagger, \S}$ Tsz Chun Yip,${ }^{\dagger}$ Lars Eric Bendel, ${ }^{\dagger}$ Wen Zhang, ${ }^{\dagger}$ and Wei- \\ Min Dai ${ }^{*} \dagger$ \\ ${ }^{\dagger}$ Hong Kong Branch of the Southern Marine Science and Engineering Guangdong Laboratory (Guangzhou), and Laboratory
of Advanced Catalysis and Synthesis, Department of Chemistry, The Hong Kong University of Science and Technology,
Clear Water Bay, Kowloon, Hong Kong SAR, P. R. of China
${ }^{\ddagger}$ School of Traditional Chinese Medicine, Southern Medical University, Guangzhou 510515, P. R. of China
$\S$ College of Chemistry, Central China Normal University, Luoyu Road 152, Hongshan District, Wuhan 430079, Hubei, P. R.
of China
}

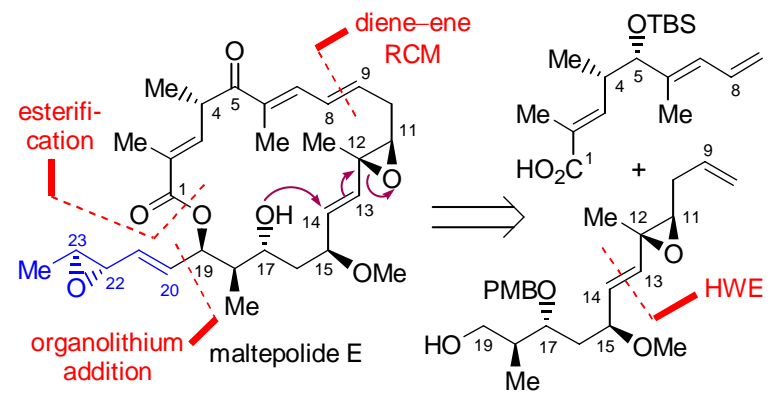

ABSTRACT: Synthesis of the C19-truncated maltepolide E has been accomplished via a diene-ene RCM strategy without damage
to the C11-C14 alkenyl epoxy unit. Upon release of the C17-OH group, it attacked at the C14 position with double bond migration
and epoxide ring-opening to furnish the C19-truncated maltepolide A and B as proposed for the biosynthesis of maltepolides.

Myxobacteria are a family of Gram-negative bacteria and produce a variety of structurally diverse secondary metabolites with significant biological activity. ${ }^{1}$ Among the known myxobacterial compounds, macrolactones are one of the abundant structural classes and exhibit antifungal, antibacterial, antiviral, and cytotoxic activity. ${ }^{1}$ Maltepolide A-F (1-6, Figure 1) were isolated from the myxobacterium Sorangium cellulosum So ce1485 originally collected from island of Malta. $^{2}$ The most abundant congener is maltepolide A (1) which was proposed as the immediate product of maltepolide E (5) formed through a favorable intramolecular vinyl epoxide ring-opening cyclization, affording a new 2,5-trans-tetrahydrofuran (THF) ring within the 20-membered macrocyclic skeleton. The minor congener, maltepolide B (2), possessing a 2,5cis-THF ring, was also obtained. Transformation of maltepolide E into maltepolide $\mathrm{A}$ and $\mathrm{B}$ has been confirmed in laboratory with isolated maltepolide $\mathrm{E}$ in the $\mathrm{pH}$ values of $<6.5$ or $>7.5$. The vinyl epoxide on the C19 side chain is susceptible to proton-mediated nucleophilic ring-opening reaction with $\mathrm{MeOH}$ or $\mathrm{H}_{2} \mathrm{O}$ to yield maltepolide C (3), D (4), and F (6). The C11,C23-bis-OTBS derivative of $\mathbf{6}$ was characterized

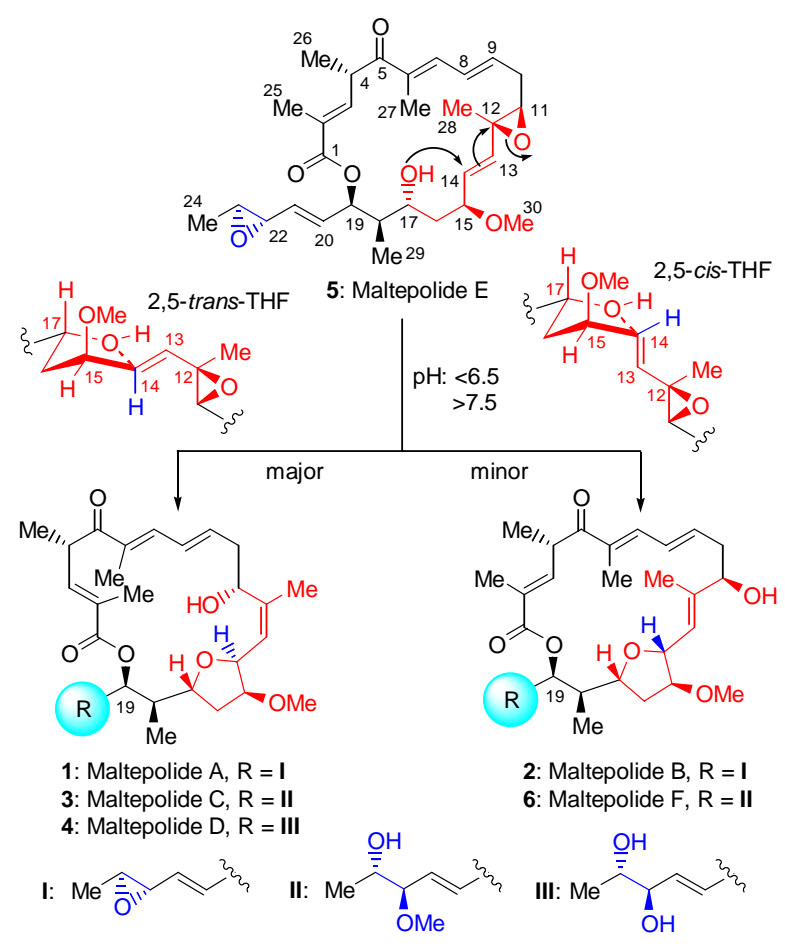

Figure 1. Structures and relationship of maltepolide A-F (1-6). 
by single crystal X-ray structural analysis, thus confirming the assigned structures. Maltepolides were assayed against a panel of transformed cell lines and moderate cytostatic activity was observed with $\mathrm{IC}_{50}$ values of 4.6 (for 3), 6.8 (for 5), $29 \mu \mathrm{M}$ (for 2), and 39 $\mu \mathrm{M}$ (for 1) against L929 mouse fibroblast cell line. ${ }^{2}$ Fluorescent microscopy study revealed unique morphological changes in the dividing transformed $\mathrm{PtK}_{2}$ cells caused by maltepolide A and E, suggesting that maltepolides could target on some kinesin ${ }^{3}$ or a factor involved in spindle assembly. ${ }^{2}$

Total synthesis of maltepolide C (3) was reported by Ghosh and co-workers, featuring an intramolecular Heck reaction to construct the $\mathrm{C} 6-\mathrm{C} 9$ diene moiety followed by $\mathrm{C} 5$ oxidation to secure the labile diene keto subunit within the macrocyclic skeleton (Scheme 1). ${ }^{4,5}$ However, the ${ }^{13} \mathrm{C}$ NMR chemical shift of one $\mathrm{MeO}$ group does not match with the reported value for the naturally occurring maltepolide $\mathrm{C}$. It is not clear at this stage about the cause of this discrepancy although a $1,4-O \rightarrow O$-silyl migration could not be ruled out during the synthesis of the $\mathrm{C} 20-\mathrm{C} 24$ side chain. ${ }^{6}$ We envisioned that synthesis of maltepolide E (5), the common precursor to other maltepolides, should be much more rewarding because it provides a quick access to other maltepolide core structures. On the practical side, it would be very challenging to concurrently handle two vinyl epoxide moieties during the synthetic sequence.

\section{Scheme 1. Retrosynthesis of Maltepolide $\mathbf{C}$ and $\mathbf{E}$}

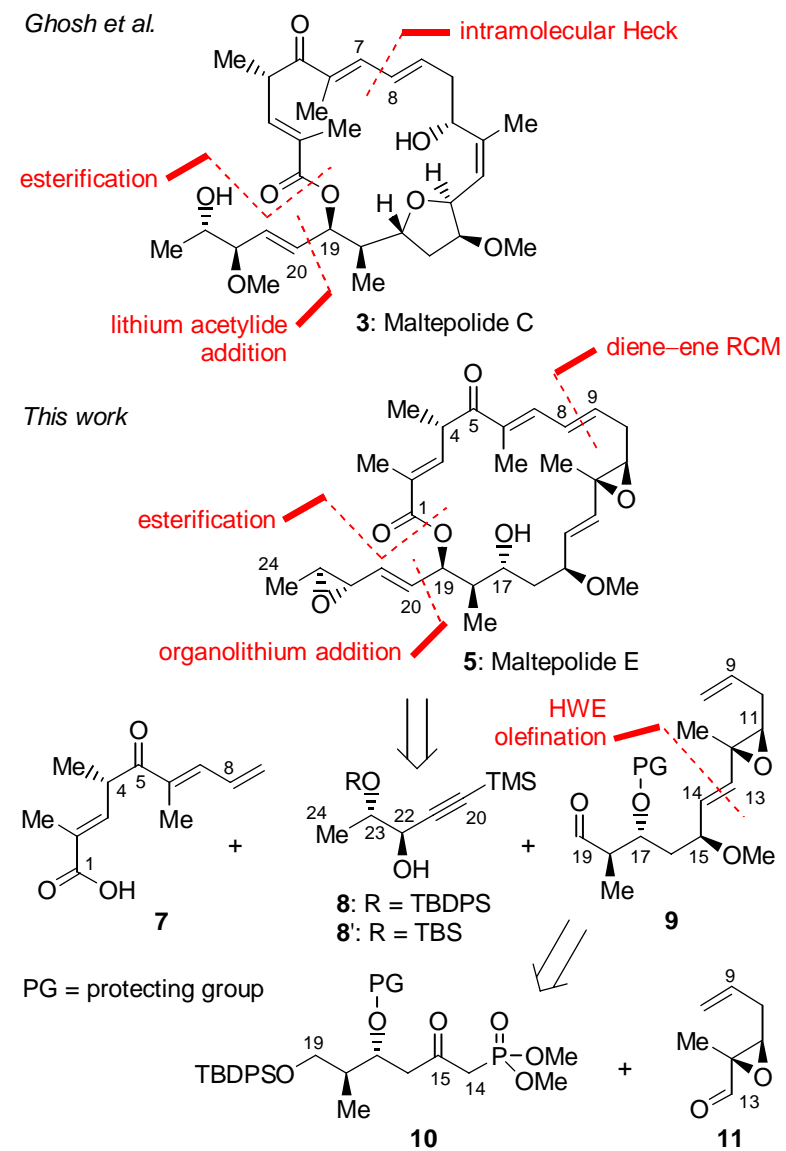

For example, the Pd-catalyzed Heck reaction conditions might not be applicable to the substrates containing a vinyl epoxide moiety. Therefore, we aimed to use a diene-ene ring-closing metathesis (RCM) strategy ${ }^{7}$ to build up the macrocyclic core of maltepolide E, from which the THF-containing core structures of maltepolide A and B could be readily accessed. According to the three key bond disconnections at the macrolactone $\mathrm{C}-\mathrm{O}$ bond, the C8/C9 double bond, and the C19/C20 single bond, three key synthetic modules 7-9 were required (Scheme 1). In order to quickly confirm the feasibility of the proposed diene-ene RCM reaction, we decided to focus on construction of the maltepolide E core without the $\mathrm{C} 20-\mathrm{C} 24$ vinyl epoxide side chain. After unsuccessful trial in installation of the C11-C15 epoxy enone via $\mathrm{Au}(\mathrm{I})$-catalyzed Meyer-Schuster rearrangement of the corresponding propargylic alcohol, ${ }^{8}$ we turned our attention to the HWE olefination between the $\beta$-keto phosphonate $\mathbf{1 0}$ and the epoxy aldehyde 11 (Scheme 1).

Synthesis of the PMB-protected C1-C8 acid 22 is illustrated in Scheme 2. An anti aldol 16 was selected

Scheme 2. Synthesis of the C1-C8 Acid Module 22
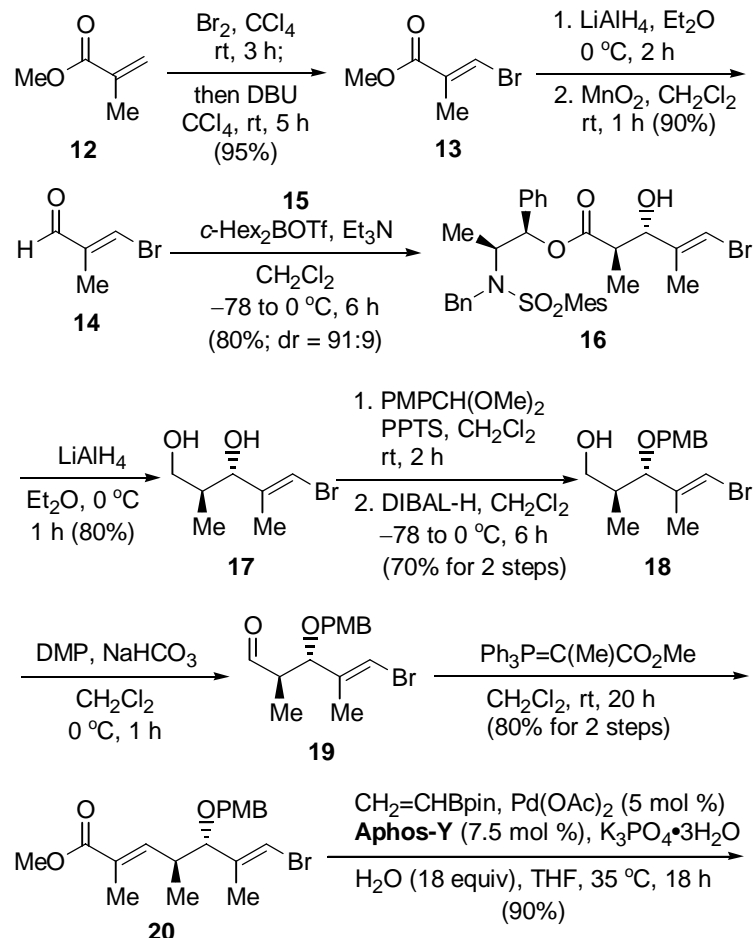

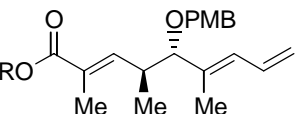

21: $\mathrm{R}=\mathrm{Me}$
22. $\mathrm{R}=\mathrm{H}$ $\begin{aligned} & \text { TMSOK, THF } \\ & \mathrm{rt}, 24 \mathrm{~h}(80 \%)\end{aligned}$

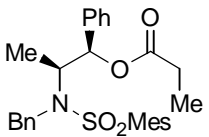

15

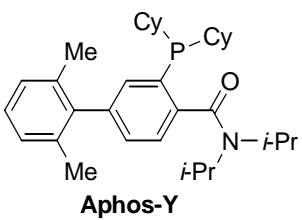


for its high stereoselectivity as the precursor of 7 . Starting from 12 the known 3-bromo-2-methylpropenal (14) ${ }^{9}$ was prepared by bromination/elimination and redox manipulation and was subjected to the antiselective aldol reaction with the chiral propionate $\mathbf{1 5}$ under the Masamune conditions. ${ }^{10,11}$ The anti aldol product 16 was obtained in $80 \%$ yield and with a diastereomeric ratio (dr) of 91:9. Reduction of $\mathbf{1 6}$ by Li$\mathrm{AlH}_{4}$ gave the 1,3-diol $17(80 \%){ }^{12}$ the latter was converted into the cyclic acetal followed by regioselective reductive acetal cleavage to furnish the primary alcohol 18 in $70 \%$ overall yield. Oxidation of $\mathbf{1 8}$ and Wittig reaction of the resultant aldehyde 19 with the ylide $\mathrm{Ph}_{3} \mathrm{P}=\mathrm{C}(\mathrm{Me}) \mathrm{CO}_{2} \mathrm{Me}$ produced the $\alpha, \beta$-unsaturated ester 20 (80\% for 2 steps). At this stage, a SuzukiMiyaura cross-coupling reaction of $\mathbf{2 0}$ with vinyl boronic acid pinacol ester was performed using our $\mathrm{Pd}(\mathrm{OAc})_{2}-$ Aphos-Y catalyst ${ }^{9,13}$ to give a $90 \%$ yield of 21 possessing the 1,3-diene moiety required for the planned RCM reaction. Finally, hydrolysis of the methyl ester 21 using TMSOK in THF gave the acid 22 in $80 \%$ yield. $^{13 c, 14}$

In order to have flexibility for functional group manipulation at late stage of the synthesis, the TBSprotected acid 28 was also prepared from 16 (Scheme 3 ). The aldehyde $\mathbf{2 5}$ was obtained via silylation of $\mathbf{1 6}$ (100\%), DIBAL-H reduction of 23 (93\%), and DMP oxidation of $24(85 \%)$. The Wittig olefination of $\mathbf{2 5}$ (91\%) followed by the Suzuki-Miyaura cross-coupling of 26 with vinyl boronic acid pinacol ester (98\%) and ester hydrolysis (95\%) furnished the acid $\mathbf{2 8}$.

Scheme 3. Synthesis of the TBS-Protected Acid 28

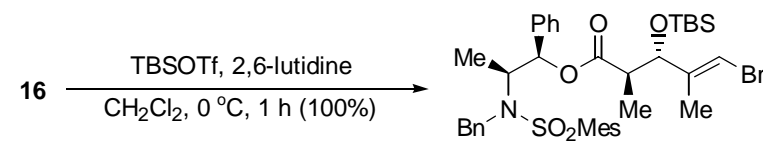

23
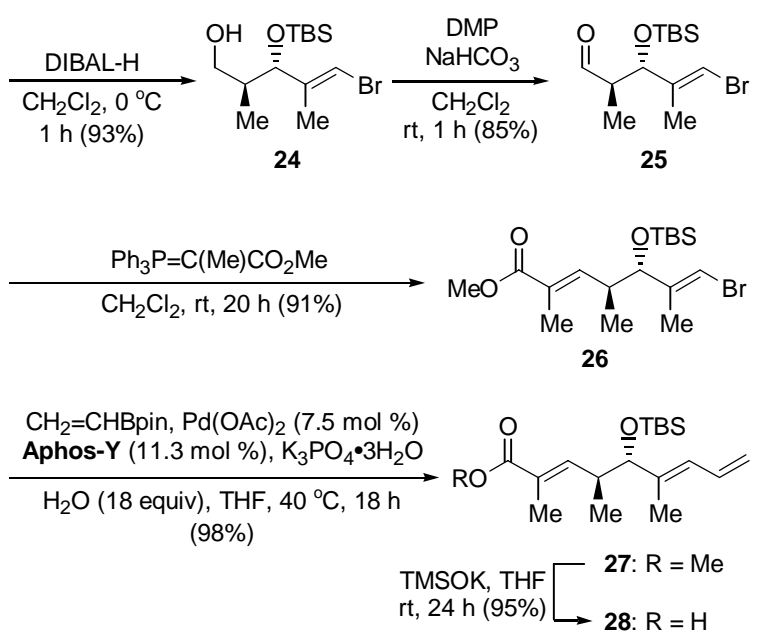

Starting from the commercially available racemic vinyl epoxide 29, the chiral epoxy aldehyde 11 was synthesized as shown in Scheme 4. The vinyl epoxide 29 was subjected to reaction with $\mathrm{CH}_{2}=\mathrm{CHMgBr}$ at -40 to 0
${ }^{\circ} \mathrm{C}$ in the presence of $10 \mathrm{~mol} \% \mathrm{CuBr}$ to form the allyl alcohol $\mathbf{3 0}$ in $86 \%$ and in a 98:2 ratio of $E: Z$ isomers. ${ }^{15}$ Sharpless asymmetric epoxidation ${ }^{16}$ of $\mathbf{3 0}$ using Ti(OiPr $)_{4}-D-(-)$-DIPT as the catalyst at $-40{ }^{\circ} \mathrm{C}$ afforded the chiral epoxy alcohol 31 in $80 \%$ yield and in $93 \%$ ee as checked by GC analysis over a chiral stationary phase. DMP oxidation of $\mathbf{3 1}$ formed $\mathbf{1 1}$ in $65 \%$ isolated yield.

\section{Scheme 4. Synthesis of the Chiral Epoxy Aldehyde 11}
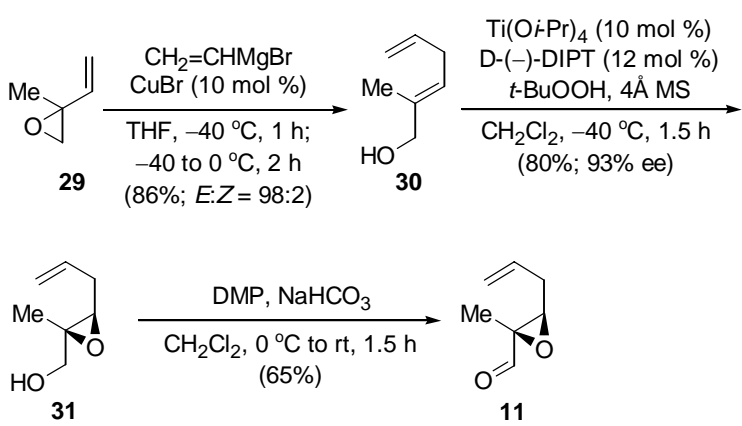

Synthesis of the $\beta$-keto phosphonate $\mathbf{4 0}$ and its HWE reaction with the epoxy aldehyde $\mathbf{1 1}$ is depicted in Scheme 5. Starting from the known homoallyl alcohol 32 prepared from $(S)$-Roche ester $(\mathbf{3 2})^{17 a}$ the cyclic acetal 33 was obtained in $81 \%$ yield by treating with DDQ under anhydrous conditions. ${ }^{17 \mathrm{~b}}$ Regioselective reductive cleavage of $\mathbf{3 3}$ using DIBAL-H gave the primary alcohol $34^{17 \mathrm{c}}$ in $89 \%$ yield. After protection of 34 as the TBDPS ether 35, its double bond was subjected to oxidative cleavage using $\mathrm{OsO}_{4}-\mathrm{NaIO}_{4}-2,6-$ lutidine under the Jin's protocol ${ }^{18}$ to form the aldehyde 36 in $87 \%$ yield. Pinnick oxidation of the aldehyde 36 gave the corresponding acid $\mathbf{3 7}$ which was transformed into the methyl ester $\mathbf{3 8}$ in $99 \%$ overall yield for the 2 steps. Deprotonation of $\mathbf{3 9}$ using $n$-BuLi (3 equiv each) at $-78^{\circ} \mathrm{C}$ formed dimethyl (lithiomethyl)phosphonate ${ }^{19}$ which reacted with the methyl ester $38\left(-78^{\circ} \mathrm{C}, 1 \mathrm{~h}\right)$ to afford the $\beta$-keto phosphonate $\mathbf{4 0}$ in $70 \%$ yield along with $28 \%$ of an enone byproduct arising from $\beta$ elimination of the PMBO group from 40. The enone by-product could be eliminated by addition of dimethyl (lithiomethyl)phosphonate with the aldehyde 36 (87\%) followed by DMP oxidation of the resultant alcohol $(88 \%)$ to furnish $\mathbf{4 0}$. HWE reaction of $\mathbf{4 0}$ with the epoxy aldehyde 11 in the presence of $\mathrm{Ba}(\mathrm{OH})_{2}$ as a mild base at room temperature produced the $(E)$-epoxy enone 41 in $87 \%$ yield. CBS reduction ${ }^{20}$ of $\mathbf{4 1}$ was first attempted with ( $R$ )-Me-CBS (1.5 equiv) and $\mathrm{BH}_{3} \cdot \mathrm{SMe}_{2}$ (2.6 equiv) in $\mathrm{THF}^{21}$ at $-15{ }^{\circ} \mathrm{C}$ for $6 \mathrm{~h}$ but the vinyl epoxide underwent spontaneous ring-opening reaction. After optimization, reduction of $\mathbf{4 1}$ with $(R)$-Me-CBS (3.3 equiv) and $\mathrm{BH}_{3} \cdot \mathrm{SMe}_{2}$ (1.05 equiv) in $\mathrm{PhMe}^{22}$ at $10{ }^{\circ} \mathrm{C}$ for $2 \mathrm{~h}$ afforded $42 \mathrm{a}$ in $75 \%$ yield without the epoxide ring-opening by-product. Alternatively, DIBAL-H reduction of $\mathbf{4 1}\left(-78{ }^{\circ} \mathrm{C}, 2 \mathrm{~h}\right)$ gave a $64: 36$ ratio of two separable alcohols $42 \mathrm{a}$ and $\mathbf{4 2 b}$ in $47 \%$ and $26 \%$ yields, respectively, along with $13 \%$ of the recovered enone 41 . The minor alcohol $42 \mathrm{~b}$ could be 3 
converted into 42a through DMP oxidation to $\mathbf{4 1}$ $(88 \%)$ and DIBAL-H reduction. Methylation of $\mathbf{4 2 a}, \mathbf{b}$ $(\mathrm{NaH}, \mathrm{MeI})$ furnished the corresponding methyl ethers 43a,b in 91-97\% yields. The ${ }^{1} \mathrm{H}$ NMR signals of C15OMe are found at 3.23 and $3.16 \mathrm{ppm}$ for $\mathbf{4 3 a}$ and $\mathbf{4 3 b}$ as compared to $3.25 \mathrm{ppm}$ for maltepolide E. ${ }^{2}$ It was assumed that 43a should have the $15 S$-configuration.

With both $\mathrm{C} 1-\mathrm{C} 8$ and $\mathrm{C} 9-\mathrm{C} 19$ modules in hand, assembly of the core structure of maltepolide $\mathrm{E}$ was executed (Scheme 6). The TBDPS ether in 43a was removed using TABF to give the alcohol 44 in $89 \%$ yield. The PMB-protected acid 22 was first used for the sequence shown in Scheme 6 and the C5,C17-bisPMB-protected analogue of the RCM product 46 was obtained as expected. However, removal of the two PMB ethers was complicated by spontaneous oxidation of the C6-C9 diene alcohol moiety under the DDQ conditions to give a complex mixture of low mass recovery. Therefore, the TBS-protected acid $\mathbf{2 8}$ was used

\section{Scheme 5. Synthesis of the C9-C19 Fragment 43a}
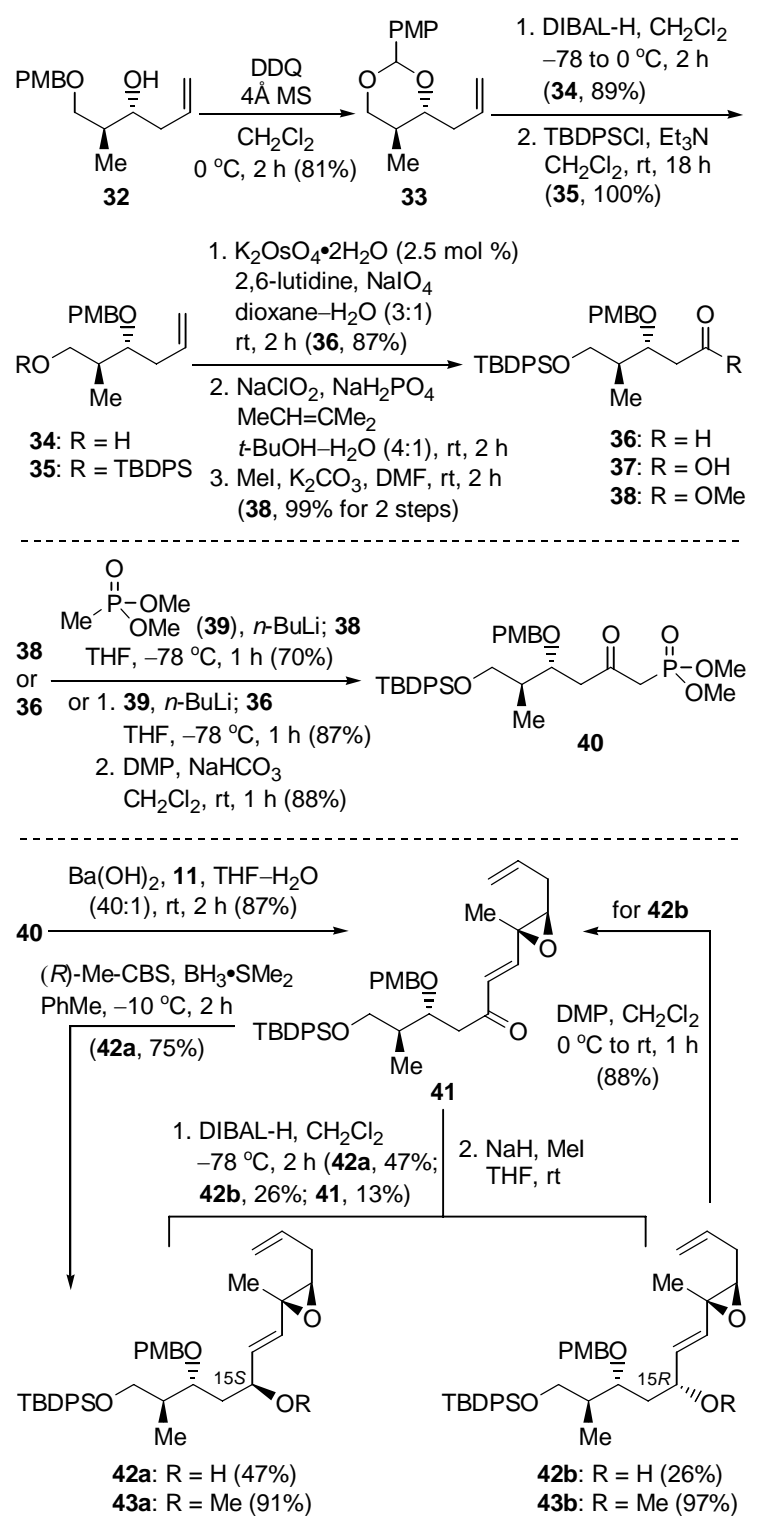

for esterification with $\mathbf{4 4}$ under the Yamaguchi conditions to form the desired ester $\mathbf{4 5}$ in $50 \%$ yield along with $43 \%$ of the benzoate byproduct formed from $\mathbf{4 4}$ and the mixed anhydride.

The seco substrate $\mathbf{4 5}$ was treated with Grubbs II catalyst $^{23,24}$ in three portions of $5 \mathrm{~mol} \%$ each (added in $8 \mathrm{~h}$ intervals) in PhMe under high dilution conditions at room temperature for $24 \mathrm{~h}$ (Scheme 6). We were pleased to note that the desired $(8 E)$-isomer 46 was exclusively formed in $67 \%$ isolated yield or $84 \%$ yield based on $20 \%$ recovery of $\mathbf{4 5}$. It was confirmed by NMR spectral data that the vinyl epoxide moiety remained intact during the RCM reaction. Selective removal of

Scheme 6. Synthesis of the Maltepolide Analogues 49-51
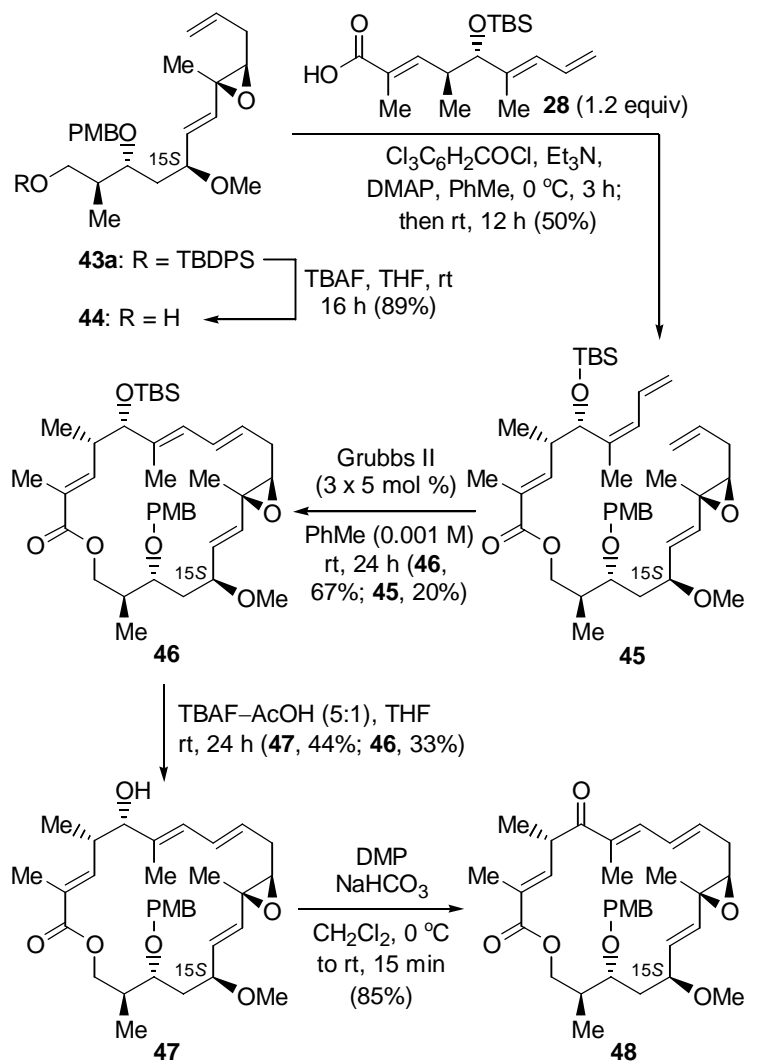

DDQ, $\mathrm{CH}_{2} \mathrm{Cl}_{2}-\mathrm{pH} 7$ bufffer (10:1)
${ }^{\circ} \mathrm{C}$ to rt, 15 min (49-51, 85\%; 48, 6\%)

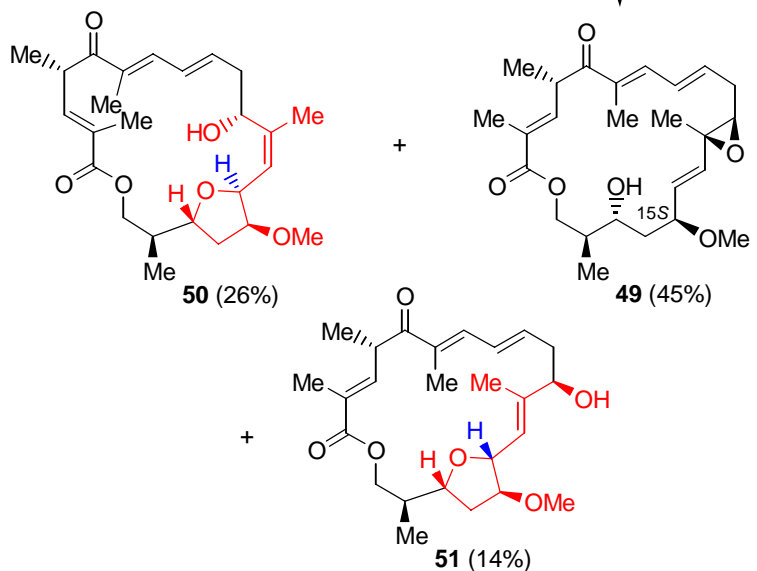


the TBS ether in 46 in mixed TBAF-AcOH (5:1) in THF (rt, $24 \mathrm{~h}$ ) gave $44 \%$ of the alcohol 47 along with $33 \%$ of the recovered 46 . Retro-aldol reaction within 47 was observed if $\mathrm{AcOH}$ was not used as the cosolvent in the TBS cleavage step. DMP oxidation of $\mathbf{4 7}$ afforded the dienone $\mathbf{4 8}$ in $85 \%$ yield. Finally, oxidative cleavage of the PMB ether in $\mathbf{4 8}$ using DDQ in $\mathrm{CH}_{2} \mathrm{Cl}_{2}$ with pH 7 buffer at $0{ }^{\circ} \mathrm{C}$ to room temperature for 15 min furnished the products $49(45 \%), \mathbf{5 0}(26 \%)$, and $\mathbf{5 1}(14 \%)$. The structures of $\mathbf{5 0}$ and $\mathbf{5 1}$ were tentatively assigned based on ${ }^{13} \mathrm{C}$ NMR signals of $\mathrm{C} 15$ $\mathrm{OMe}$ at $57.8(\mathbf{5 0})$ and $57.2(\mathbf{5 1}) \mathrm{ppm}$ as compared to 57.9 (1) and 57.3 (2) ppm, respectively. Moreover, the 2,5-trans-THF ring in $\mathbf{5 0}$ formed in a greater portion than the 2,5-cis-THF ring in $\mathbf{5 1}$ in a good agreement with the conversion of maltepolide $\mathrm{E}(\mathbf{5})$ into maltepolide A (1) and B (2). ${ }^{2}$ Comparison of ${ }^{13} \mathrm{C}$ NMR data of the C19-truncated maltepolide A and B with those of the natural products is illustrated in Figure 2. Except for C17-C19, the chemical shifts of other carbons in the C19-truncated maltepolide A (50) are within the differences of $\leq \pm 0.75 \mathrm{ppm}$. For the $\mathrm{C} 19$-truncated maltepolide B (51), C11, C14, C17-C19, and C28 have the chemical shift differences of $\geq \pm 0.82 \mathrm{ppm}$, indicating the $\mathrm{C} 20-\mathrm{C} 24$ side chain exerting a greater influence on the core conformation of $\mathbf{5 1}$.

(a)

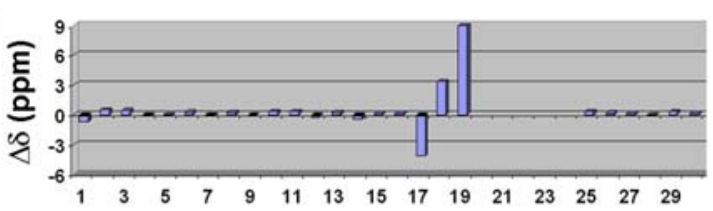

(b)

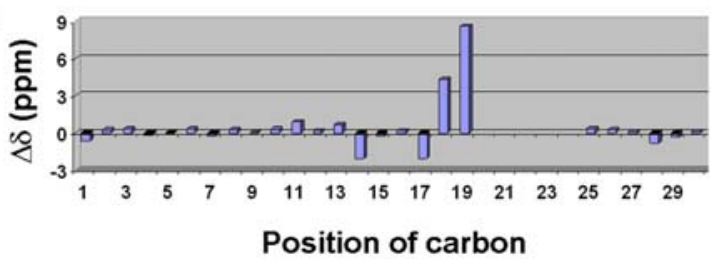

Figure 2. Comparison of ${ }^{13} \mathrm{C}$ NMR data of $\mathbf{5 0}$ (a) and $\mathbf{5 1}$ (b) with maltepolide $\mathrm{A}(\mathbf{1})$ and $\mathrm{B}(2)$ recorded in $\mathrm{CD}_{3} \mathrm{OD} . \Delta \delta=$ $\delta$ (natural) $-\delta$ (synthetic)

A preliminary assay of cytotoxicity against L929 mouse fibroblast cell line was performed for the C19truncated maltepolide core structures and precursors (Table 1). Among the five tested samples, the compound $\mathbf{4 8}$ gave the best cancer cell inhibitory activity with time-dependent $\mathrm{IC}_{50}$ values in the range of ca. 20 $\mu \mathrm{M}$ after incubation for 24,48 , and $72 \mathrm{~h}$, respectively. In contrast, the closed related compound $\mathbf{4 6}$ was inactive in the same assay, indicating irrelevance of the vinyl epoxide and the importance of the conjugated dienyl keto unit for the observed anticancer activity. Comparison of other three samples 49-51 possessing the same conjugated dienyl keto unit reveals that the macrolactone ring structure also affects the cytotoxicity. The C19-truncated maltepolide A $\mathbf{5 0}$ was inactive while the C19-truncated maltepolide B $\mathbf{5 1}$ showed moderate activity. It is assumed that the $\mathrm{C} 19$-truncated maltepolide E 49 could be transformed into $\mathbf{5 0}$ and $\mathbf{5 1}$ under the incubation conditions; 49 might deliver cancer cell killing effect through the action of 51. This assumption is consistent with the observed diminished $\mathrm{IC}_{50}$ values of 49 as compared to those of 51 by $1.2-$ 1.7 folds after incubation for 24,48 , and $72 \mathrm{~h}$, respectively. The cytotoxicity data of $\mathbf{4 9 - 5 1}$ also suggest that the side chain appended at $\mathrm{C} 19$ of maltepolide A, B, C, and $\mathrm{E}$ play a key role in the biological function.

Table 1. $\mathrm{IC}_{50}(\mu \mathrm{M})$ against L929 mouse fibroblast cell line ${ }^{\mathrm{a}}$

\begin{tabular}{cccc}
\hline Compound & $24 \mathrm{~h}$ & $48 \mathrm{~h}$ & $72 \mathrm{~h}$ \\
\hline $\mathbf{4 6}$ & - & - & - \\
$\mathbf{4 8}$ & $20.56 \pm 0.99$ & $16.50 \pm 0.92$ & $16.55 \pm 0.83$ \\
$\mathbf{4 9}$ & $160.5 \pm 22.5$ & $145.9 \pm 17.6$ & $119.3 \pm 20.2$ \\
$\mathbf{5 0}$ & - & - & - \\
$\mathbf{5 1}$ & $138.5 \pm 18.6$ & $145.9 \pm 17.6$ & $72.28 \pm 20.03$ \\
\hline
\end{tabular}

${ }^{a}$ MTT assay was used for incubation with the samples for 24 , 48 , and $72 \mathrm{~h}$, respectively.

In summary, we have established a diene-ene RCM strategy for assembling the macrolactone cores of maltepolides. It has been confirmed that the $\mathrm{C} 11-\mathrm{C} 14$ alkenyl epoxy moiety in maltepolide $\mathrm{E}$ could survive the $\mathrm{Ru}(\mathrm{II})$ catalysis conditions. The finding implies that our RCM strategy would be applicable for construction of the fully functionalized maltepolide E, possessing another alkenyl epoxy moiety on the $\mathrm{C} 20-\mathrm{C} 24$ side chain. The synthesized C19-truncated maltepolide E analogue 49 underwent intramolecular epoxide ringopening cyclization to form the corresponding maltepolide A and B analogues $\mathbf{5 0}$ and $\mathbf{5 1}$ under mild conditions in a similar manner as proposed for the naturally occurring maltepolide E (1), proving additional evidence to support the biosynthetic pathways. ${ }^{2}$ Moreover, the preliminary cytotoxicity data against L929 mouse fibroblast cell line demonstrate the importance of the conjugated dienyl keto unit in inhibiting cancer cell growth which might account for the highest activity reported for maltepolide C (3) although much more work should be done in future studies.

\section{ASSOCIATED CONTENT}

\section{Supporting Information}

The Supporting Information is available free of charge on the ACS Publications website.

Experimental procedures, compound characterization data, and copies of original ${ }^{1} \mathrm{H}$ and ${ }^{13} \mathrm{C}$ NMR spectra (PDF)

\section{AUTHOR INFORMATION}

\section{Corresponding Authors}

*E-mail: chdai@ust.hk

\section{ORCID}

Hui Hui Cao: 0000-0001-5297-4702

Wei-Min Dai: 0000-0001-5688-7606

Man Ki Sit: 0000-0003-1465-2782 
Yan-Dong Wu: 0000-0003-0589-7155

Tsz Chun Yip: 0000-0001-6430-1169

Wen Zhang: 0000-0003-4504-7438

\section{ACKNOWLEDGMENT}

This work is supported in part by a General Research Fund grant (16301014) from the Research Grant Council, The Hong Kong Special Administrative Region, P. R. China, the Hong Kong Branch of Southern Marine Science and Engineering Guangdong Laboratory (Guangzhou) (SMSEGL20SC01), and the Department of Chemistry, HKUST.

\section{REFERENCES}

(1) For recent reviews, see: (a) Hermann, J.; Fayad, A. A.; Müller, R. Natural Products from Myxobacteria: Novel Metabolites and Bbioactivities. Nat. Prod. Rep. 2017, 34, 135-160. (b) Dehhaghi, M.; Mohammadipanah, F.; Guillemin, G. J. Myxobacterial Natural Products: An Undervalued Source of Products for Drug Discovery for Neurological Disorders. NeuroToxicology 2018, 66, 195-203.

(2) For isolation of maltepolides, see: Irschik, H.; Washausen, P.; Sasse, F.; Fohrer, J.; Huch, V.; Müller, R.; Prusov, E. V. Isolation, Structure Elucidation, and Biological Activity of Maltepolides: Remarkable Macrolides from Myxobacteria. Angew. Chem. Int. Ed. 2013, 52, 5402-5405.

(3) Kapoor, T. M.; Mayer, T. U.; Coughlin, M. L.; Mitchison, T. J. Probing Spindle Assembly Mechanisms with Monastrol, a Small Molecule Inhibitor of the Mitotic Kinesin, Eg5. J. Cell Biol. 2000, 150, 975-988.

(4) For total synthesis of the proposed structure of maltepolide C, see: Rao, K. N.; Kanakaraju, M.; Kunwar, A. C.; Ghosh, S. Total Synthesis of the Proposed Structure of Maltepolide C. Org. Lett. 2016, 18, 4092-4095.

(5) For synthesis of fragments of maltepolides, see: (a) Mohapatra, D. K.; Reddy, D. S.; Reddy, G. S.; Yadav, J. S. Synthesis of the C-8-C-24 Fragment of Maltepolide C by Using a Tandem Dihydroxtlation $/ \mathrm{S}_{\mathrm{N}} 2$ Cyclization Sequence. Eur. J. Org. Chem. 2015, 5266-5274. (b) Rao, P. S.; Srihari, P. A Facile Approach for the Synthesis of C13-C24 Fragments of Maltepolides A, C and D. Org. Biomol. Chem. 2016, 14, 9629-9638.

(6) According to our experiments, $1,4-O \rightarrow O$-silyl migration occurred when removal of TMS in $\mathbf{8}$ (Scheme 1) in the presence of $\mathrm{K}_{2} \mathrm{CO}_{3}$ in $\mathrm{MeOH}$ at $0{ }^{\circ} \mathrm{C}$ to room temperature, resulting in a mixture of the C22-OTBDPS homopropargylic alcohol (rearranged) and the C23-OTBDPS propargylic alcohol. Methylation of the TBS analogue $\mathbf{8}^{\prime}$ by using $\mathrm{NaH}-\mathrm{MeI}$ at $0{ }^{\circ} \mathrm{C}$ (reported in Ref. 4) might accompany with TBS migration. For known examples of silyl migration, see: (a) Mulzer, J.; Schölhorn, B. Multiple 1,2-O,O-Shift of tert-Butyldiphenylsilyl Groups in Polyols. Angew. Chem. Int. Ed. 1990, 29, 431-432. (b) Hillier, M. C.; Meyers, A. I. Investigation of a Novel Sequential 1,5 O $\rightarrow$ O Silyl Migration/Horner-WadsworthEmmons Reaction. Tetrahedron Lett. 2001, 42, 5145-5147. (c) Furegati, S.; White, A. J. P.; Miller, A. D. Observation of a 1,5Silyl-Migration on Fructose. Synlett 2005, 2385-2387. (d) Sun L.; Wu, D.; Wu, J.; Dai, W.-M. Concise Diverted Total Synthesis of Amphidinolide T1 and T4 from a (12E)-Cycloalkene by Selective Functionalization of the C12-C13 Double Bond. Synlett 2011, 3036-3040. (e) Perali, R. S.; Mandeva, S.; Chunduri, V. R. An Unexpected Migration of $O$-Silyl Group under Mitsunobu Reaction Conditions. Tetrahedron Lett. 2011, 52, 3045-3047. (f) Sanchez, L.; Smith, III, A. B. Long-Range Anion Relay Chemistry (LR-ARC): A Validated ARC Tactic. Org. Lett. 2012, 14, 6314-6317. (g) Pu, Q.; Tang, X.; Gao, L.; Song, Z. Three-Component Reaction to Synthesize E-Vinyl Silyl anti-1,2-Diols via Sequential [1,4]-O-to-O/[1,4]C-to-O Silyl Migrations. Org. Chem. Front. 2018, 5, 2035-2039. (h) Zhang, W.; Ma, H.; Li, C.-C.; Dai, W.-M. Synthesis of the C6C18 Bis-tetrahydrofuran Fragment of the Proposed Structure of Iriomoteolide-2a via Stepwise Double $\mathrm{S}_{\mathrm{N}} 2$ Cyclization Reactions. Tetrahedron 2019, 75, 1795-1807. (i) Holmstedt, S.; Efimov, A.; Candeisa, N. R. O,O-Silyl Group Migration in Quinic Acid Deriva- tives: An Opportunity for Divergent Synthesis. Org. Lett. 2021, 23, 3083-3087.

(7) For examples of diene-ene RCM reaction, see: (a) Sun, L.; Feng, G.; Guan, Y.; Liu, Y.; Wu, J.; Dai, W.-M. Influence of Appended Groups on the Formation of 16-Membered Macrolactone Core Related to the Plecomacrolides via Diene-Ene Ring-Closing Metathesis. Synlett 2009, 2361-2365. (b) Du, J.-Y.; An, X.-T.; Zhao, X.-H.; Ma, X.-Y.; Cao, Y.-X.; Fan, C. A. Synthetic Studies toward Melotenine A. Tetrahedron 2019, 75, 1760-1766.

(8) For recent reviews, see: (a) Engel, D. A.; Dudley, G. B. The Meyer-Schuster Rearrangement for the Synthesis of $\alpha, \beta$ Unsaturated Carbonyl Compounds. Org. Biomol. Chem. 2009, 7, 4149-4158. (b) Cadierno, V.; Crochet, P.; García-Garrido, S. E.; Gimeno, J. Metal-Catalyzed Transformations of Propargylic Alcohols into $\alpha, \beta$-Unsaturated Carbonyl Compounds: From the MeyerSchuster and Rupe Rearrangements to Redoxisomerizations. Dalton Trans. 2010, 39, 4015-4031. (c) Zhang, L.; Fang, G.; Kumar, R. K.; $\mathrm{Bi}, \mathrm{X}$. Coinage-Metal-Catalyzed Reactions of Propargylic Alcohols. Synthesis 2015, 47, 2317-2346.

(9) Wang, Y.; Dai, W.-M. Synthesis of the Conjugated Tetraene Acid Side Chain of Mycolactone E by Suzuki-Miyaura CrossCoupling Reaction of Alkenyl Boronates. Eur. J. Org. Chem. 2014, 323-330.

(10) (a) Abiko, A.; Liu, J.-F. Masamune, S. The Anti-Selective Boron-Mediated Asymmetric Aldol Reaction of Carboxylic Esters. J. Am. Chem. Soc. 1997, 119, 2586-2587. (b) Inoue, T.; Liu, J.-F.; Buske, D.C.; Abiko, A. Boron-Mediated Aldol Reaction of Carboxylic Esters: Complementary Anti- and Syn-Selective Asymmetric Aldol Reactions. J. Org. Chem. 2002, 67, 5250-5256.

(11) For reviews, see: (a) Abiko, A. Boron-Mediated Aldol Reaction of Carboxylic Esters. Acc. Chem. Res. 2004, 37, 387-395. (b) Cruz, A.; Padilla-Martínez, I. I.; Bautista-Ramírez, M. E. Ephedrines as Chiral Auxiliaries in Enantioselective Alkylation Reactions of Acyl Ephedrine Amides and Esters: A Review. Curr. Org. Synth. 2018, 15, 38-83.

(12) Kiho, T.; Nakayama, M.; Kogen, H. Total Synthesis and NMR Conformational Study of Signal Peptidase II Inhibitors, Globomycin and SF-1902 A5. Tetrahedron 2003, 59, 1685-1697.

(13) (a) Dai, W.-M.; Li, Y.; Zhang, Y.; Lai, K. W.; Wu, J. A Novel Class of Amide-Derived Air-Stable P,O-Ligands for Suzuki Cross-Coupling at Low Catalyst Loading. Tetrahedron Lett. 2004, 45, 1999-2001. (b) Dai, W.-M.; Zhang, Y. A Family of Simple Amide-Derived Air-Stable P,O-Ligands for Suzuki Cross-Coupling of Unactivated Aryl Chlorides. Tetrahedron Lett. 2005, 46, 13771381. (c) Jin, J.; Chen, Y.; Li, Y.; Wu, J.; Dai, W.-M. Total Synthesis of Amphidinolide Y by Formation of Trisubstituted (E)-Double Bond via Ring-Closing Metathesis of Densely Functionalized Alkenes. Org. Lett. 2007, 9, 2585-2588. (d) Dai, W.-M.; Li, Y.; Zhang, Y.; Yue, C.; Wu, J. Generation of an Aromatic AmideDerived Phosphane (Aphos) Library by Self-Assisted Molecular Editing and Applications of Aphos in Room-Temperature SuzukiMiyaura Reactions. Chem. Eur. J. 2008, 14, 5538-5554. (e) Sun, L.; Dai, W.-M. Determination of Absolute Configuration of 2-Methyl1-(o-tolyl)naphthalene and the Related Axially Chiral Biaryls. Tetrahedron 2011, 67, 9072-9079. (f) Ye, N.; Dai, W.-M. An Efficient and Reliable Catalyst System Using Hemilabile Aphos for B-Alkyl Suzuki-Miyaura Cross-Coupling Reaction with Alkenyl Halides. Eur. J. Org. Chem. 2013, 831-835. (g) Cui, C.; Dai, W.-M. Total Synthesis of Laingolide B Stereoisomers and Assignment of Absolute Configuration. Org. Lett. 2018, 20, 3358-3361.

(14) Laganis, E. D.; Chenard, B. L. Metal Silanolates: Organic Soluble Equivalents for $\mathrm{O}^{-2}$. Tetrahedron Lett. 1984, 25, 58315834.

(15) For $\mathrm{S}_{\mathrm{N}} 2^{\prime}$ addition of organocopper reagents with vinyloxiranes, see: (a) Marshall, J. A. $\mathrm{S}_{\mathrm{N}} 2^{\prime}$ Additions of Organocopper Reagents to Vinyloxiranes. Chem. Rev. 1989, 89, 1503-1511. (b) Jung, M. E.; D'Amico, D. C. Stereospecific Rearrangement of Optically Active Tertiary Allylic Epoxides to Give Optically Active Quaternary Aldehydes: Synthesis of $\alpha$-Alkyl Amino Aldehydes and Acids. J. Am. Chem. Soc. 1995, 117, 7379-7388. (c) Cahiez, C.; Alexakis, A.; Normant, J. F. A Highly Stereoselective Preparation6 of 1,4- and 1,5-Alkadienes. Synthesis 1978, 528-530. 
(16) (a) Gao, Y.; Hanson, R. M.; Klunder, J. M.; Ko, S. Y.; Masamune, H.; Sharpless, K. B. Catalytic Asymmetric Epoxidation and Kinetic Resolution: Modified Procedures Including in Site Derivatization. J. Am. Chem. Soc. 1987, 109, 5765-5780. (b) Prasad, K. R.; Pawar, A. B. Enantioselective Formal Synthesis of Palmerolide A. Org. Lett. 2011, 13, 4252-4255. (c) Baldwin, J. E.; Bulger, P. G.; Marquez, R. Fast and Efficient Synthesis of Novel Fumagillin Analogues. Tetrahedron 2002, 58, 5441-5452.

(17) (a) Feyen, F.; Jantsch, A.; Altmann, K.-H. Synthetic Studies on Mycolactones: Synthesis of the Mycolactone Core Structure through Ring-Closing Olefin Metathesis. Synlett 2007, 415-418. (b) Fuwa, H.; Mizunuma, K.; Matsukida, S.; Sasaki, M. A New Strategy for the Synthesis of Substituted Dihydropyrones and Tetrahydropyrones via Palladium-Catalyzed Coupling of Thioesters. Tetrahedron 2011, 67, 4995-5010. (c) Ko, K.-S.; Alexander, M. D.; Fontaine, S. D.; Biggs-Houck, J. E.; La Clair, J. J.; Burkart, M. D. Synthetic Studies on the Macolactone Core. Org. Biomol. Chem. 2010, 8, 5159-5165.

(18) Yu, W.; Mei, Y.; Kang, Y.; Hua, Z.; Jin, Z. Improved Procedure for the Oxidative Cleavage of Olefins by $\mathrm{OsO}_{4}-\mathrm{NaIO}_{4}$. Org. Lett. 2004, 6, 3217-3219.

(19) (a) Marshall, J. A.; Sedrani, R. A Convergent, Highly Stereoselective Synthesis of a C-11-C-21 Subunit of the Macbecins. J. Org. Chem. 1991, 56, 5496-5498. (b) Delamarche, I.; Mosset, P. New Syntheses of Some Functionalized and Acetylenic $\beta$-Keto Phosphates. J. Org. Chem. 1994, 59, 5453-5457. (c) Evans, M. A.; Morken, J. P. Asymmetric Synthesis of (-)-Dihydroxanthatin by the Stereoselective Oshima-Utimoto Reaction. Org. Lett. 2005, 7, 3371-3373.

(20) For reviews on CBS reduction, see: (a) Corey, E. J.; Helal, C. J. Reduction of Carbonyl Compounds with Chiral Oxazaborolidine Catalysts: A New Paradigm for Enantioselective Catalysis and a Powerful New Synthetic Method. Angew. Chem. Int. Ed. 1998, 37, 1986-2012. (b) Heravi, M. M.; Asadi, S.; Nazari, N.; Lashkariani, B. M. Application of Corey-Bakshi-Shibata, CoreyKim, Corey-Seebach, Corey-Winter, Corey-Link, and CoreyGanem-Gilman in Organic and Total Synthesis. Monatsh Chem. 2016, 147, 961-987.

(21) Corey, E. J.; Bakshi, R. K.; Shibata, S. Highly Enantioselective Borane Reduction of Ketones Catalyzed by Chiral Oxazaborolidines. Mechanism and Synthetic Implications. J. Am. Chem. Soc. 1987, 109, 5551-5553.

(22) For CBS reduction of $\gamma, \delta$-epoxy- $\alpha, \beta$-enone in $\mathrm{PhMe}$, see: Krauss, I. J.; Mandal, M.; Danishefsky, S. J. Total Synthesis of (+)Isomigrastatin. Angew. Chem. Int. Ed. 2007, 46, 5576-5579.

(23) Scholl, M.; Ding, S.; Lee, C. W.; Grubbs, R. H. Synthesis and Activity of a New Generation of Ruthenium-Based Olefin Metathesis Catalysts Coordinated with 1,3-Dimethyl-4,5dihydroimidazol-2-ylidene Ligands. Org. Lett. 1999, 1, 953-956.

(24) For selected reviews on Ru-catalyzed RCM in total synthesis, see: (a) Fürstner, A. Olefin Metathesis and Beyond. Angew. Chem. Int. Ed. 2000, 39, 3012-3043; (b) Nicolaou, K. C.; Bulger, P. G.; Sarlah, D. Metathesis Reactions in Total Synthesis. Angew. Chem. Int. Ed. 2005, 44, 4490-4527; (c) Gradillas, A.; PérezCastells, J. Macrocyclization by Ring-Closing Metathesis in the Total Synthesis of Natural Products: Reaction Conditions and Limitations. Angew. Chem. Int. Ed. 2006, 45, 6086-6101; (d) Fürstner, A. Metathesis in Total Synthesis. Chem. Commun. 2011, 47, 65056511; (e) Fürstner, A. Teaching Metathesis "Simple" Stereochemistry. Science 2013, 341, 1229713; (f) Hoveyda, A. H. Evolution of Catalytic Stereoselective Olefin Metathesis: From Ancillary Transformation to Purveyor of Stereochemical Identity. J. Org. Chem. 2014, 79, 4763-4792; (g) Fuwa, H.; Sasaki, M. Exploiting Ruthenium Carbene-Catalyzed Reactions in Total Synthesis of Marine Oxacyclic Natural Products. Bull. Chem. Soc. Jpn. 2016, 89, 14031415; (h) Ogba, O. M.; Warner, N. C.; O'Leary, D. J.; Grubbs, R. H. Recent Advances in Ruthenium-Based Olefin Metathesis. Chem. Soc. Rev. 2018, 47, 4510-4544. (i) Cheng-Sánchez, I; Sarabla, F. Recent Advances in Total Synthesis via Metathesis Reactions. Synthesis 2018, 50, 3749-3786. (j) Kajetanowicz, A. Grela, K. Nitro and Other Electron Withdrawing Group Activated Ruthenium Cata- lysts for Olefin Metathesis Reactions. Angew. Chem. Int. Ed. 2021 , 60, 13738-13756. 